\title{
Cone-beam computed tomography observation of maxillary first premolar canal shapes
}

\author{
Takafumi Yoza ${ }^{1}$, Masamitsu Serikawa ${ }^{1}$, Toshihiro Sugita ${ }^{2}$, Takuya Harada $^{3}$, Akinobu Usami $^{1}$ \\ ${ }^{1}$ Department of Morphological Biology, Ohu University School of Dentistry, Koriyama, ${ }^{2}$ Department of General Odontology, Ohu University Graduate \\ School of Dentistry, Koriyama, ${ }^{3}$ Department of Oral Radiology and Diagnosis, Ohu University School of Dentistry, Koriyama, Japan
}

\begin{abstract}
A variety of shapes has been reported for the roots and root canals of maxillary first premolars. The purposes of the present study were to determine branching and shapes of the roots of maxillary first premolars, as well as age-related changes using slice images obtained with cone-beam computed tomography (CBCT) for dental use. CBCT-reconstructed images of 125 cases that included maxillary first premolars were used as subjects. Slice images at the cervical one-third, center, and apical one-third positions of the root were prepared. Root branching and number of root canals was determined at each measurement position in the images. The subjects were divided into three groups: younger than 30 years, 30 to 50 years, and over 50 years. The root canal morphology was compared among these age groups. Single-rooted premolars were the most frequent. As for number of root canals, a single-canal premolar was observed at the position of the cervical one-third in $33.6 \%$, at the center in $35.2 \%$, and at the apical one-third in $56.0 \%$. Thereafter the subjects were divided into groups by age, namely, younger than 30 years, 30 to 50 years, and over 50 years old, and it was revealed that the ratio of the two-canal type increased with age. In regard to tooth morphology, it was confirmed that the two-canal type shows more frequent occurrence with aging in maxillary first premolar. Based on our findings, we consider that CBCT can be useful for determining the root canal morphology with complicated shapes.
\end{abstract}

Key words: Maxillary first premolar, Cone-beam computed tomography, Aging, Root canal

Received May 31, 2021; Revised June 21, 2021; Accepted June 24, 2021

\section{Introduction}

An accurate understanding of individual dental morphology is important for proper dental treatment, though a wide variety of roots and root canal shapes of maxillary first premolars has been reported [1-11] .Thus far, most observations have been made using extracted and India ink-stained premolars, and transparent root canal specimens [1-3], or dental X-ray images [4-8]. However, cone-beam computed tomog-

\section{Corresponding author:}

Akinobu Usami (iD

Department of Morphological Biology, Ohu University School of Dentistry, Koriyama, Fukushima 963-8611, Japan

E-mail: a-usami@den.ohu-u.ac.jp raphy (CBCT) has recently been found useful for diagnosis based on detailed observations of the internal structures of hard tissues [10-13].

Maxillary first premolar root branching has been reported in various studies, with the occurrence of a single-rooted premolar reported in $11.7 \%$ to $39.5 \%$ of examined cases, whereas the occurrence rate of a two-rooted premolar ranged from $56.5 \%$ to $86.0 \%[1,3,4]$. Furthermore, ethnicity-related differences in regard to root shape are known, as multiplerooted maxillary premolars are a characteristic in Caucasian subjects $[3,4]$. There are also various reports regarding the number of root canals. For determining root canal morphology, the classification of Vertucci $[1,2]$, in which shape was divided into 8 types by ramification patterns, and that reported by Pineda and Kuttler [5] showing the number of root canal ends at the root apex, have been used.

\section{Copyright (c) 2021. Anatomy \& Cell Biology}

This is an Open Access article distributed under the terms of the Creative Commons Attribution Non-Commercial License (http://creativecommons.org/licenses/by-nc/4.0/) which permits unrestricted non-commercial use, distribution, and reproduction in any medium, provided the original work is properly cited. 
It is considered that root canal shape changes with age. However, few quantitative investigations of this issue have been presented. The present study was conducted using $\mathrm{CBCT}$ for the purpose of determining the number of roots and root canal shapes, as well as age-related changes of maxillary first premolars in Japanese subjects.
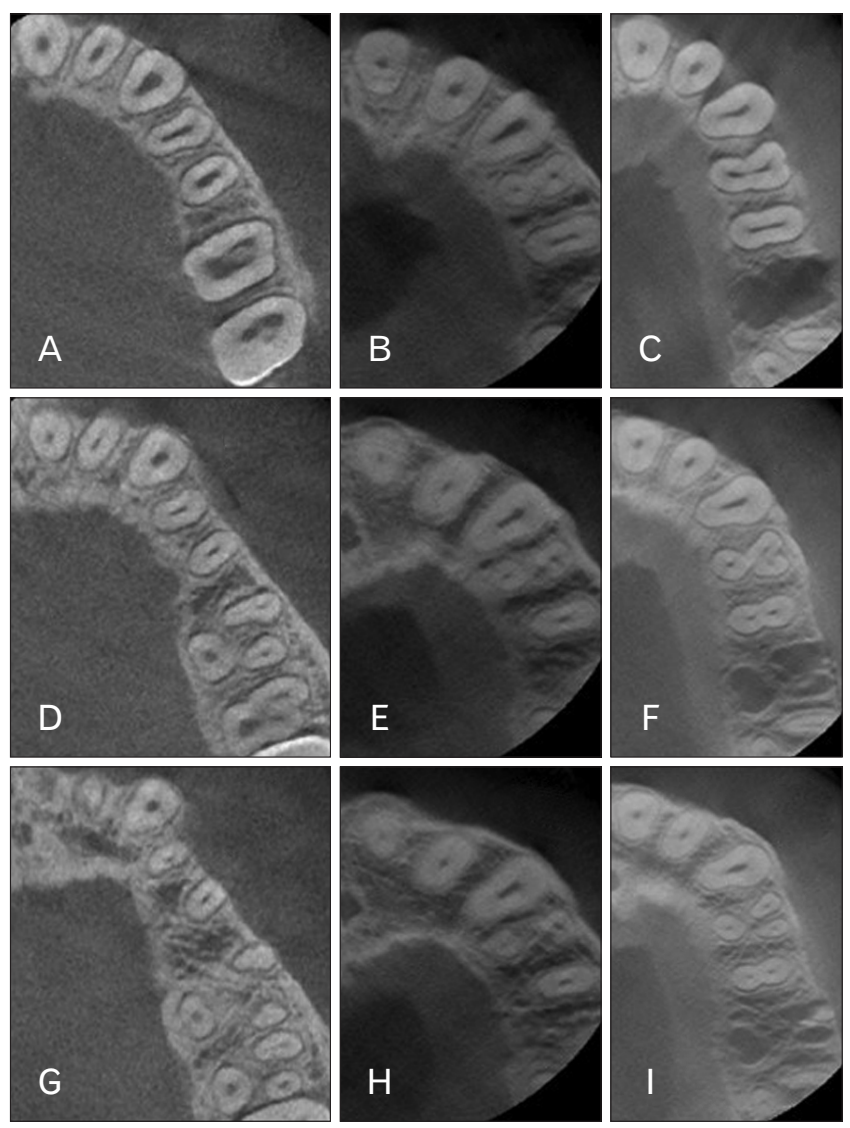

Fig. 1. The axial slice images of cone-beam computed tomography (CBCT) revealed different numbers of roots of the maxillary first premolars. Slice images at cervical one-third (A-C), root center (D-F), and apical one-third $(G-I)$. Slice images of one root $(A, D, G)$, two roots $(\mathrm{B}, \mathrm{E}, \mathrm{H})$, and three roots $(\mathrm{C}, \mathrm{F}, \mathrm{I})$.

\section{Materials and Methods}

CBCT-reconstructed images of premolars without root canal treatment from a total of 125 subjects (58 males, 67 females; age range 12-69 years) were obtained using a 3DX Multi Image Micro CT FPD (J. Morita MFG Corp., Tokyo, Japan) at Ohu University School of Dentistry Hospital. The criteria for inclusion in the study were as follows [11]:

- Entire maxillary first premolar included in imaging range

- Dental root growth completed

- No root resorption or radiolucent area in root apex

- No canal filling or prosthesis in post or crown

- Clear and complete images available

Using the Morita One Volume Viewer imaging software package (J. Morita MFG Corp.), reconstructed images vertical to the tooth axis were obtained, then slice images of the dental root at the cervical one-third, center, and apical onethird positions were prepared to observe root shape (Fig. 1). For morphological observation of root canals, binary images were prepared using the Image J public domain software program [14], with the range of the maxillary first premolar root selected on each slice image. Binary images were processed using image data within the root range as the baseline. For the measurement items, the number of branching roots was confirmed in each slice image for assessment of root shape and the number of root canals was also determined in each slice image using binary images for observation of the root canal shapes (Fig. 2). Moreover, the subjects were divided into three groups according to the age, younger than 30 years consisting of 52 cases, between $30-50$ years, 50 cases; and over 50 years, 23 cases.

The present study protocol was approved by the Ethics Committee of Ohu University (No. 234).
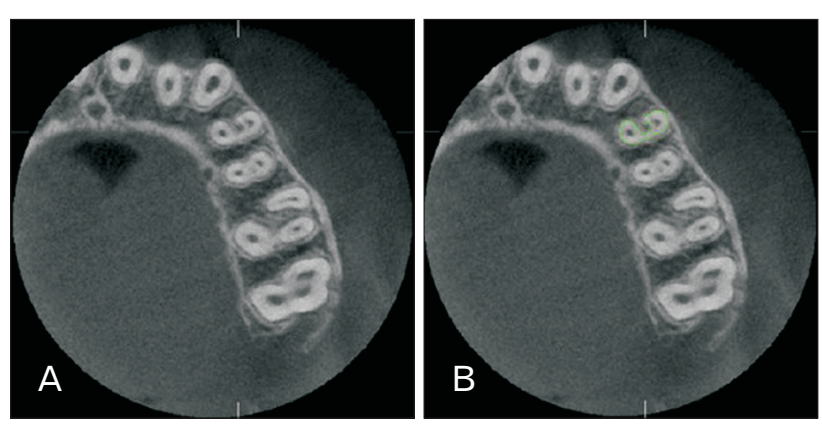

Fig. 2. Binary image processing. (A) Slice image of root center of left maxillary first premolar. (B) Image analyzed using peri-root portion as area of interest. (C) Binary image of area of interest. 
Table 1. Numbers of roots and root canals

\begin{tabular}{lccc}
\hline \multicolumn{1}{c}{ No. of roots } & 1 & 2 & 3 \\
\hline No. of root canals & 1 & 2 & 3 \\
Cervical one-third & $42(33.6)$ & $82(65.6)$ & $1(0.8)$ \\
Root center & $44(35.2)$ & $79(63.2)$ & $2(1.6)$ \\
Apical one-third & $70(56.0)$ & $53(42.4)$ & $2(1.6)$ \\
Total & $101(80.8)$ & $22(17.6)$ & $2(1.6)$ \\
\hline
\end{tabular}

Values are presented as number only or number (\%).

\section{Results}

A single-rooted type was confirmed in 101 cases, accounting for $80.8 \%$, while two-rooted type was seen in $22(17.6 \%)$ and three-rooted in $2(1.6 \%)$ cases (Table 1). As for root canal shape at the cervical one-third, a single canal type was observed in 42 cases (33.6\%), a two canal type in 82 cases (65.5\%), and a three canal type in 1 case $(0.8 \%)$. At the root center, $44(35.2 \%)$ were found to have a single root canal, $79(63.2 \%)$ two root canals, and $2(1.6 \%)$ three root canals. Findings for root canal shape at the apical one-third position showed 70 cases $(56.0 \%)$ with a single root canal, 53 (42.4\%) with two root canals, and 2 (1.6\%) with three root canals (Table 1).

The most frequent combination of root canal number at the cervical one-third, root center, and apical one-third was 2-2-2, which was observed in 47 cases (37.6\%), followed by 1-1-1 observed in 32 cases (25.6\%), and 2-2-1 observed in 23 cases (18.4\%). Furthermore, a 2-1-1 combination was observed in 11 cases (8.8\%), 1-2-2 in 5 cases (4.0\%), 1-2-1 in 4 cases $(3.2 \%)$ and $1-1-2$ in 1 case $(0.8 \%)$. There was no incidence of 2-1-2 observed in the present cases (Table 2).

For classification of root canal shape by age group, at the cervical one-third position, a single canal was observed in $50.0 \%$, two canals in $48.1 \%$, and three canals in $1.9 \%$ of the group younger than 30 years old. In the group aged 30-50 years, single, two, and three canals were noted in $28.0 \%$, $72.0 \%$, and $0 \%$, respectively, while in the group older than 50 years the percentages were $8.7 \%, 91.3 \%$, and $0 \%$, respectively. At the root center position in the group younger than 30 years, single, two, and three canals were seen in $51.9 \%$, $44.2 \%$, and $3.8 \%$, respectively. Those percentages in the group aged $30-50$ years were $26.0 \%, 74.0 \%$, and $0 \%$, respectively, and in the group older than 50 years were $17.4 \%$, $82.6 \%$, and $0 \%$, respectively. Finally, for the apical one-third position single, two, and three canals were noted in $61.5 \%$, $34.6 \%$, and $3.8 \%$, respectively, in the group younger than 30 years, $58.0 \%, 42.0 \%$, and $0 \%$, respectively, in the group aged
Table 2. Classification of root canal shapes of maxillary first premolars and rate of occurrence of each type

\begin{tabular}{ccc}
\hline Root canal shapes & No. of occurrences & Rate of occurrence (\%) \\
\hline $1-1-1$ & 32 & 25.6 \\
$1-1-2$ & 1 & 0.8 \\
$1-2-1$ & 4 & 3.2 \\
$1-2-2$ & 5 & 4.0 \\
$2-1-1$ & 11 & 8.8 \\
$2-1-2$ & 0 & 0 \\
$2-2-1$ & 23 & 18.4 \\
$2-2-2$ & 47 & 37.6 \\
$2-3-3$ & 1 & 0.8 \\
$3-3-3$ & 1 & 0.8 \\
Total & 125 & 100 \\
\hline
\end{tabular}

The figure of the root canal shapes from the left side presented the number of the root canals at cervical one-third, center and apical one-third, respectively.

$30-50$ years, and $39.1 \%, 60.9 \%$, and $0 \%$, respectively, in the group older than 50 years (Fig. 3, Table 3).

\section{Discussion}

The internal structures of teeth are complicated and difficult to understand by dental X-ray imaging alone. However, with the availability of CBCT, the internal structures of hard tissues are now able to be visualized in a three-dimensional manner [12]. Although patient radiation dose with CBCT is generally higher as compared to panoramic X-ray imaging, effective dose from CBCT is lower than multislice CT [13].

For radiographic diagnosis, it has been reported that radiolucency on the apical side is decreased due to increased dentin and alveolar bone in teeth with two root canals $[1,8]$. On the other hand, it is very difficult to precisely visualize root canal shapes using two-dimensional radiography [12].

In the AAE/AAOMR Joint Position Statement on use of CBCT in Endodontics, CBCT is suggested to be a useful diagnostic imaging procedure for cases with a complicated and irregular root canal morphology [15]. Accordingly, it is also recommended that for diagnosing root canal morphology, proper utilization of CBCT is important so as to reduce exposure by use of the correct field of view setting. CBCT produces gray scale images without CT values, thus various techniques have been reported for measurements, including observation by a single examiner [16], reliability confirmation of measured data by use of a Kappa test after multiple measurements [17], and determinations on the basis of consensus of multiple examiners [18-21].

Blattner et al. [18] reported findings of a study in which the number of root canals was determined based on consen- 

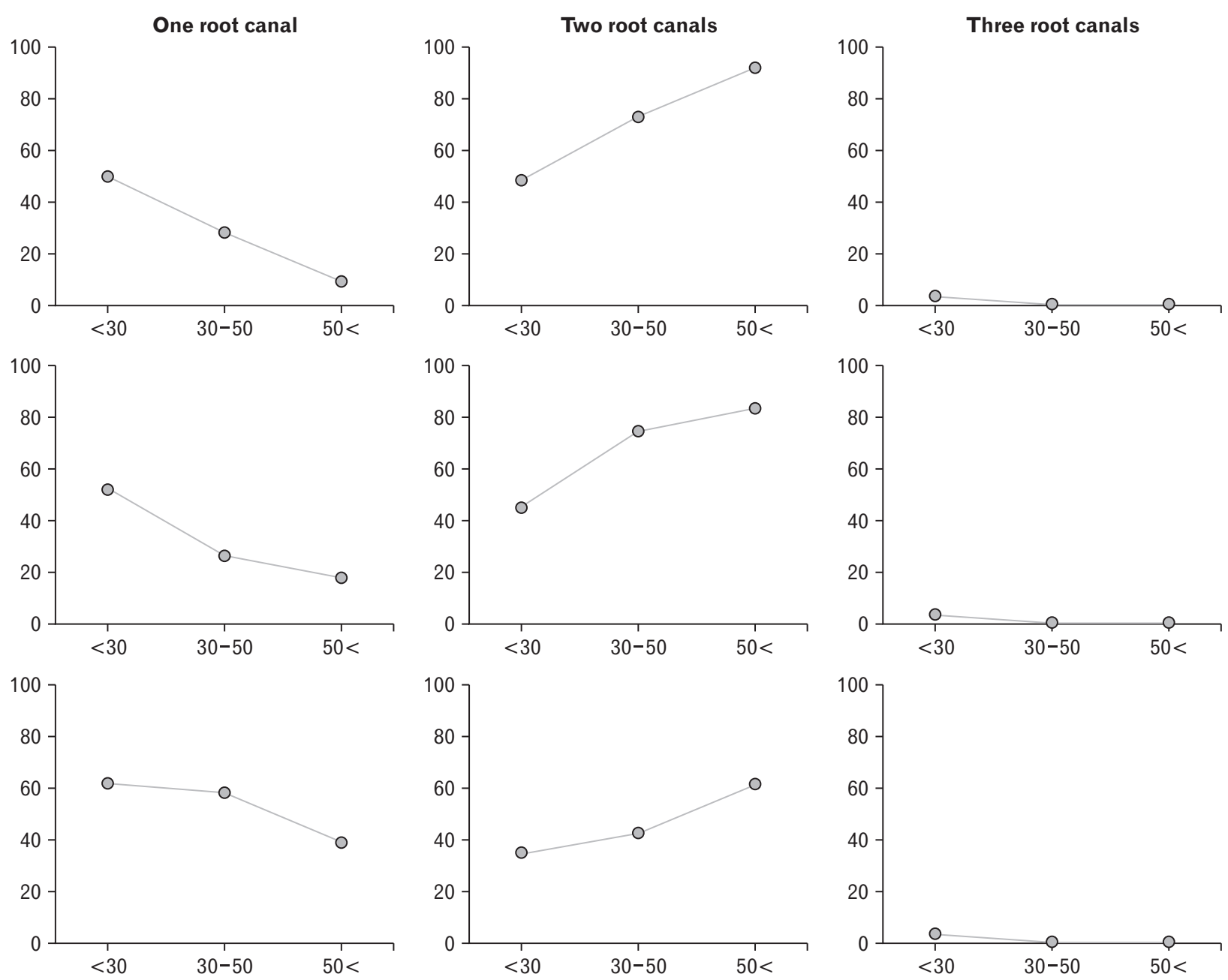

Fig. 3. Root canal numbers of the maxillary first premolars divided by age. Left: Occurrence of single canal. Center: Occurrence of two canals. Right: Occurrence of three canals. The shape at the cervical one-third, root center, and apical one-third is shown in the upper, middle, and bottom, respectively. Charts show occurrence after dividing into age groups (from the left: $<30,30-50,50<$ years old).

Table 3. Root canals numbers of the maxillary first premolars in each age group

\begin{tabular}{|c|c|c|c|c|c|c|c|c|c|}
\hline \multirow{2}{*}{ Position of the root } & \multicolumn{3}{|c|}{ One root canal } & \multicolumn{3}{|c|}{ Two root canals } & \multicolumn{3}{|c|}{ Three root canals } \\
\hline & $<30 \mathrm{yr}$ & $30-50 \mathrm{yr}$ & $>50 \mathrm{yr}$ & $<30 \mathrm{yr}$ & $30-50 \mathrm{yr}$ & $>50 \mathrm{yr}$ & $<30 \mathrm{yr}$ & $30-50 \mathrm{yr}$ & $>50 \mathrm{yr}$ \\
\hline Cervical third (\%) & 50.0 & 28.0 & 8.7 & 48.1 & 72.0 & 91.3 & 1.9 & 0.0 & 0.0 \\
\hline Root center (\%) & 51.9 & 26.0 & 17.4 & 44.2 & 74.0 & 82.6 & 3.8 & 0.0 & 0.0 \\
\hline Apical third (\%) & 61.5 & 58.0 & 39.1 & 34.6 & 42.0 & 60.9 & 3.8 & 0.0 & 0.0 \\
\hline
\end{tabular}

Groups were divided into three: younger than 30 years, 30-50 years, and over 50 years.

sus agreement by an oral and maxillofacial radiologist and endodontist regarding second mesiobuccal canal emergence rate in the mesiobuccal root of maxillary first and second molars using extracted teeth, and they showed a high correlation between CBCT findings and actual observations. It was also reported that deviations among examiners can be avoided by using an image processing technique for assessment of the smear layer of dentin in scanning electric microscope gray-scale images $[22,23]$. In the present study, the root canal shapes were extracted by binary image processing after selecting the inside of the outer configuration of the roots on CBCT slice images using the Image J software package [14], thus allowing analysis of root canal shapes with reference to the binary image obtained.

Various classifications have been reported for root canal shape observations. Vertucci [2] prepared transparent root 
canal specimens of maxillary first premolars and categorized them as type I to VIII, though only the root canal shapes were classified, irrespective of root morphology. In the present study, premolars were examined in the plane vertical to the tooth axis for observing the shapes of both the root and root canals. It has been suggested that the pulp chamber does not transit to the root canal at the level of the cementenamel junction, as the pulp floor base is closer to the apical side from the cervical line [24]. Accordingly, the shapes of the roots and root canals were observed using CBCT slice images at the cervical one-third, center, and apical one-third positions of the root in the present study.

Vertucci [2] prepared transparent root canal subjects using maxillary first premolars from subjects whose age, gender, ethnicity, and reason for extraction were unknown, and found that Type IV, which indicates separation into two from the root canal orifice to the apical foramen, was found in $62.0 \%$. Of the premolars from Japanese subjects used in the present study, two canals at the cervical one-third, center, and apical one-third (2-2-2) positions was observed in 47 of 125 cases $(37.6 \%)$.

The rate of occurrence of three-rooted maxillary premolars has been reported to range from $0.5 \%-9.2 \%[1,4,5]$, which has been termed small or radiculous molar $[3,8]$. The frequency of three rooted maxillary first premolar was 1.0\% in Chinese subpopulation [25]. Beltes et al. [10] observed three-rooted maxillary premolars and reported that all had two roots on the buccal side and a single root on the palatal side, whereas Neelakantan et al. [3] reported frequent occurrence of two roots on the palatal side and a single root on the buccal side in Indian population. In the present investigation, a three-rooted maxillary first premolar was observed in only $2(1.6 \%)$ cases, and both had two roots on the buccal side and one root on the palatal side.

It has been suggested that a three-rooted maxillary premolar is a characteristic of the Caucasian subjects $[3,4]$. In a report of CBCT findings of a Spanish population, three-rooted premolars were found in $2.6 \%$ [11], while the frequency was $9.2 \%$ in a Polish population [4].

With two canals, the radiolucency of the root canal is changed $[1,8]$ and it has also been reported that radiolucency is drastically decreased in images of three-rooted maxillary premolars [5]. Pineda and Kuttler [5] reported the frequency of three root canals in premolar was $0.5 \%$, whereas Vertucci noted 1.25\% [2] and Sieraski et al. 5\%-6\% [7]. In the present study of Japanese subjects, three canals at the center-apical side were observed in $1.6 \%$. It has also been noted that the radiolucency of the pulp chamber was suddenly decreased in cases with three canals $[6,24]$. As for the characteristics of the outer shape of a maxillary first premolar with three canals, it was reported that the mesiodistal diameter at the root center was frequently the same or larger than that of the crown [7]. In the present study, a similar tendency was observed in three canal premolars.

It is impossible to distinguish reparative dentin caused by stimulation from the addition of secondary dentin due to aging [24], as formation of secondary dentin continues throughout life, which narrows the pulp cavity [26]. However, few reports are available regarding the relationship between root canal morphology and age. Pineda and Kuttler [5] compared X-ray findings of various root canals in subjects divided into discontinuous three age groups; younger than 25 years, 35-45 years, and over 55 years, and reported findings showed that the root canal diameter was reduced with age, though the authors did not provide morphological measurements of the root canals or compare shapes. There were some teeth used in the present study exist in the interstice of these age group. So, we classified root canal shape among subjects younger than 30 years, 30-50 years, and older than 50 years. There was difference of the root canal shapes among three age groups. It might be effected by the addition of secondary dentin. It has been shown that the maxillary first premolar begins calcification at the age of 1.5 years, then erupts at the age of 10-11 years and completes root growth at 12-13 years old [27]. Among the subjects used for root canal measurements in the present study, the youngest subject was 12 years old, who showed a seemingly fully-grown root in CBCT images, while the oldest was 69 years.

Slowey [9] reported that teeth with two roots and two canals were frequently seen among maxillary first premolars, while those with a single root and two canals were occasionally noted. They also found that teeth with two root canals were frequently continued via a narrowed canal isthmus in some with a single root. In the present study, a comparison of maxillary first premolar root canal shapes among the groups divided by younger than 30 years, $30-50$ years, and over 50 years of age revealed that the ratio of teeth with two root canals increased with age.

It was reported $68.8 \%$ of the maxillary first premolars have mesial concavity [28]. The mesial and distal wall of the pulp chamber of the maxillary first premolar often bulge prominently into lumen [29]. So, the root canal might be ef- 
fected by the root shape. This was considered to be the result of root canal morphological changes caused by addition of secondary dentin in the pulp chamber.

In conclusion, a finding of a single root was the most frequent among the maxillary first premolars observed in the present study at apical one- third of the roots. As for the root canal, teeth with a root canal morphology of 2-2-2 (two canals at the cervical one-third, root center, and apical onethird positions) were most frequently observed. When we analyzed root canal shapes, it was observed that the ratio of premolars with two canals was increased with age. Based on our findings, we concluded that CBCT is useful for determining the root canal shapes of maxillary first premolars, which are known to have a complicated morphology.

\section{ORCID}

Takafumi Yoza: https://orcid.org/0000-0001-9472-666X Masamitsu Serikawa:

https://orcid.org/0000-0002-7557-790X

Toshihiro Sugita: https://orcid.org/0000-0002-1047-7764

Takuya Harada: https://orcid.org/0000-0003-1021-1111

Akinobu Usami: https://orcid.org/0000-0002-3929-0346

\section{Author Contributions}

Conceptualization: TY, AU. Data acquisition: TY, MS. Data analysis or interpretation: TY, TS, AU. Drafting of the manuscript: TY, AU. Critical revision of the manuscript: TS, $\mathrm{TH}, \mathrm{AU}$. Approval of the final version of the manuscript: all authors.

\section{Conflicts of Interest}

No potential conflict of interest relevant to this article was reported.

\section{References}

1. Vertucci FJ, Gegauff A. Root canal morphology of the maxillary first premolar. J Am Dent Assoc 1979;99:194-8.

2. Vertucci FJ. Root canal anatomy of the human permanent teeth. Oral Surg Oral Med Oral Pathol 1984;58:589-99.

3. Neelakantan P, Subbarao C, Ahuja R, Subbarao CV. Root and canal morphology of Indian maxillary premolars by a modified root canal staining technique. Odontology 2011;99:18-21.

4. Lipski M, Wozniak K, Lagocka R, Tomasik M. Root and canal morphology of the first human maxillary premolar. Durham
Anthropol J 2005;12:2-3.

5. Pineda F, Kuttler Y. Mesiodistal and buccolingual roentgenographic investigation of 7,275 root canals. Oral Surg Oral Med Oral Pathol 1972;33:101-10.

6. Soares JA, Leonardo RT. Root canal treatment of three-rooted maxillary first and second premolars--a case report. Int Endod J 2003;36:705-10.

7. Sieraski SM, Taylor GN, Kohn RA. Identification and endodontic management of three-canalled maxillary premolars. J Endod 1989;15:29-32.

8. Javidi M, Zarei M, Vatanpour M. Endodontic treatment of a radiculous maxillary premolar: a case report. J Oral Sci 2008;50:99-102.

9. Slowey RR. Root canal anatomy. Road map to successful endodontics. Dent Clin North Am 1979;23:555-73.

10. Beltes P, Kalaitzoglou ME, Kantilieraki E, Beltes C, Angelopoulos C. 3-rooted maxillary first premolars: an ex vivo study of external and internal morphologies. J Endod 2017;43:126772.

11. Abella F, Teixidó LM, Patel S, Sosa F, Duran-Sindreu F, Roig M. Cone-beam computed tomography analysis of the root canal morphology of maxillary first and second premolars in a Spanish population. J Endod 2015;41:1241-7.

12. Berman LH, Hartwell GR. Diagnosis. In: Hargreaves KM, Cohen S, editors. Cohen's Pathways of the Pulp. 10th ed. St. Louis: Elsevier; 2011. p.2-39.

13. Suomalainen A, Pakbaznejad Esmaeili E, Robinson S. Dentomaxillofacial imaging with panoramic views and cone beam CT. Insights Imaging 2015;6:1-16.

14. Schneider CA, Rasband WS, Eliceiri KW. NIH image to Image): 25 years of image analysis. Nat Methods 2012;9:671-5.

15. Special Committee to Revise the Joint AAE/AAOMR Position Statement on use of CBCT in Endodontics. AAE and AAOMR joint position statement: use of cone beam computed tomography in endodontics 2015 update. Oral Surg Oral Med Oral Pathol Oral Radiol 2015;120:508-12.

16. Katakami K, Mishima A, Shiozaki K, Shimoda S, Hamada Y, Kobayashi K. Characteristics of accessory mental foramina observed on limited cone-beam computed tomography images. J Endod 2008;34:1441-5.

17. Kim SY, Yang SE. Cone-beam computed tomography study of incidence of distolingual root and distance from distolingual canal to buccal cortical bone of mandibular first molars in a Korean population. J Endod 2012;38:301-4.

18. Blattner TC, George N, Lee CC, Kumar V, Yelton CD. Efficacy of cone-beam computed tomography as a modality to accurately identify the presence of second mesiobuccal canals in maxillary first and second molars: a pilot study. J Endod 2010;36:86770 .

19. Vizzotto MB, Silveira PF, Arús NA, Montagner F, Gomes BP, da Silveira HE. CBCT for the assessment of second mesiobuccal (MB2) canals in maxillary molar teeth: effect of voxel size and presence of root filling. Int Endod J 2013;46:870-6.

20. Morikage N, Hamada T, Usami A, Takada S. Topographical 
relationship between positions of lingual foramina and attachment of mylohyoid muscle in mental region. Surg Radiol Anat 2017;39:735-9.

21. Bulut DG, Kose E, Ozcan G, Sekerci AE, Canger EM, Sisman Y. Evaluation of root morphology and root canal configuration of premolars in the Turkish individuals using cone beam computed tomography. Eur J Dent 2015;9:551-7.

22. George R, Rutley EB, Walsh LJ. Evaluation of smear layer: a comparison of automated image analysis versus expert observers. J Endod 2008;34:999-1002.

23. Schmidt TF, Teixeira CS, Felippe MC, Felippe WT, Pashley $\mathrm{DH}$, Bortoluzzi EA. Effect of ultrasonic activation of irrigants on smear layer removal. J Endod 2015;41:1359-63.

24. Nelson S. Pulp chambers and canals. In: Nelson S, editor. Wheeler's Dental Anatomy, Physiology and Occlusion. 10th ed.
St. Louis: Elsevier; 2015. p.203-30.

25. Tian YY, Guo B, Zhang R, Yu X, Wang H, Hu T, Dummer PM. Root and canal morphology of maxillary first premolars in a Chinese subpopulation evaluated using cone-beam computed tomography. Int Endod J 2012;45:996-1003.

26. Berkovitz BKB. Oral cavity. In: Standring S, editor. Gray's Anatomy. 41st ed. Livingstone: Elsevier; 2016. p.507-33.

27. Nelson S. Development and eruption of the teeth. In: Nelson S, editor. Wheeler's Dental Anatomy, Physiology and Occlusion. 10th ed. St. Louis: Elsevier; 2015. p.21-42.

28. Fan L, Yuan K, Niu C, Ma R, Huang Z. A cone-beam computed tomography study of the mesial cervical concavity of maxillary first premolars. Arch Oral Biol 2018;92:79-82.

29. Sicher H, Dubrul EL. The viscera. In: Sicher H, DuBrul EL, editors. Oral Anatomy. 6th ed. St Louis: Mosby; 1975. p.192-298. 